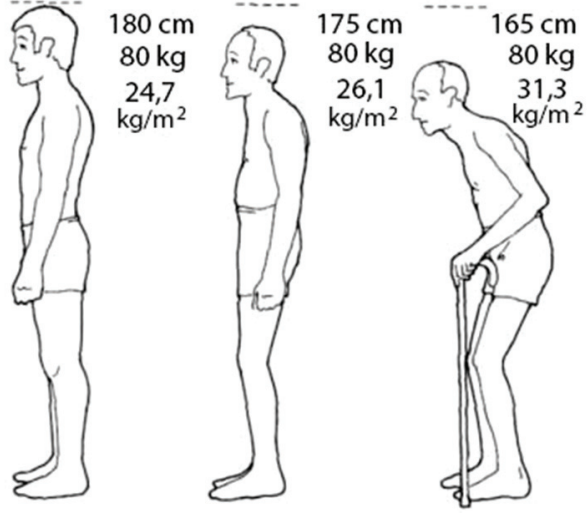

Figure 1. Difference in BMI in the person with unstable height and stable body mass.

Objectives: To evaluate changes in height and BMl over time in patients with axSpA, treated with tumor necrosis factor- $\alpha$ inhibitors (iTNF- $\alpha$ ). Methods: The study included 51 patients with axSpA (ASAS criteria 2009). All the patients were treated with iTNF- $\alpha$ for one and $>$ years. The patient's height and weight measured before the beginning TNF- $\alpha$ inhibitors and during the treatment. Only patients with stable weight (variability $\pm 2.0 \mathrm{~kg}$ from baseline) were included in the study.

Results: Mean age of axSpA patients at baseline was $40.22 \pm 13.51,38$ $(74.5 \%)$ were male, disease duration $12.77 \pm 6.82$, duration of TNF- $\alpha$ inhibitors treatment $5.64 \pm 2.21$ years, all the patients had inactive disease. In 19 patients with axSpA diagnostic delay was 8 years.

Patients' height varied between $1.55-1.92 \mathrm{~m}$ (average height 1.73 \pm 0.07 $\mathrm{m})$. Male's mean height was $1.78 \pm 0.05 \mathrm{~m}$, women's - $1.63 \pm 0.05 \mathrm{~m}$. Height decrease over time in patients with AxSpa was $3.74 \pm 1.83 \mathrm{~cm}$ (from 1.0 to $15.0 \mathrm{~cm}$ ). Maximal decrease in height was shown in patients with 10 years after the first symptoms emerged. Mean weight in patients who had height loss was $79.75 \pm 12.7 \mathrm{~kg}$. Among patients who had decrease of height and stable body mass the difference between BMI at subsequent measurement and the time of treatment initiation $(\Delta \mathrm{BMI})$ was $1.15 \mathrm{~kg} / \mathrm{m}^{2}$ : BMl at baseline $=26.25 \pm 3.34 \mathrm{~kg} / \mathrm{m}^{2}$, over time of observation $\mathrm{BMI}=27.39 \pm 3.38 \mathrm{~kg} / \mathrm{m}^{2}$ ).

Conclusion: Height loss in axSpA is significant even in patients with inactive disease. Height loss affects BMI calculation that could lead to overestimation of cardiovascular risk, obesity and could change all of the BMI-dependent areas. Correction of BMI calculation for the patients with unstable height is needed.

Disclosure of Interests: Elizaveta Vasilenko: None declared, Olga Nikolaeva: None declared, Anna Dadalova: None declared, Ekaterina Gaydukova: None declared, V Mazurov Grant/research support from: JSC BIOCAD, Inna Gaydukova Grant/research support from: JSC BIOCAD, Speakers bureau: paiment from Pfizer, Novartis, Abbvie, Biocad, Selgene, MSD, Sanofy not exceed 10000 euros

DOI: 10.1136/annrheumdis-2019-eular.5994

\section{AB0734B BONY BRIDGE ON FACET JOINT OR LATERAL SIDE OF LUMBAR VERTEBRA IS MORE FREQUENT AND CORRELATED WITH LUMBAR FLEXION FUNCTION THAN THAT ON ANTERIOR SIDE OF LUMBAR VERTEBRA IN ANKYLOSING SPONDYLITIS; ANALYSIS OF ANKYLOSIS REGISTRY OF AXIAL SPONDYLOARTHRITIS (ANKAS)}

So Yun Lee ${ }^{1}$, Seong Jong Yun ${ }^{2}$, Ran Song ${ }^{1}$, Sang-Hoon Lee ${ }^{1} .{ }^{1}$ Kyung Hee University, Hospital at Gangdong, Rheumatology, Seoul, Korea, Rep. of (South Korea); ${ }^{2}$ Kyung Hee University, Hospital at Gangdong, Radiology, Seoul, Korea, Rep. of (South Korea)

Background: Ankylosing spondylitis (AS) is a form of chronic inflammatory arthritis characterized by sacroilitis and a marked propensity for sacroiliac joint and spinal fusion. The modified Stoke Ankylosing Spondylitis Spinal Score (mSASSS) has been used when measuring radiographic progression in AS, which only measures bony changes of anterior side in vertebral body (AV). Variation of this score is too small to assess radiographic progression in AS. Some patients have syndesmophytes on lateral side in vertebral body (LV) or ankylosis in facet joints (FJ).
Objectives: We planned this study to know which side of lumbar vertebra ankylosis more frequently develops in and is more correlated with lumbar flexion function.

Methods: We analyzed ANKylosis registry of Axial Spondyloarthritis (ANKAS). In this cohort, the patients with AS are examined by anteroposterior and lateral view of $\mathrm{X}$-ray every 2 years and low dose whole spine computed tomography (CT) every 5 years to determine radiographic progression. We analyzed the location of near total or total bone bridge at each level of lumbar spine by X-ray and CT in 518 patients with AS. Results: Male was $78 \%$ and mean age was $38.8 \pm 2.8$. Ankylosis or bony bridge in sacroiliac joint (SIJ), FJ, LV and AV was respectively $55.2 \%, 22.8 \%, 21.6 \%$ and $13.1 \%$. T12L1 was the most frequent level of ankylosis in FJ (31.7\%) and LV (30.3\%). For FJ and LV, there was a tendency that upper levels of spine have more ankylosis, but not in AV. The patients who didn't have SIJ ankylosis also have a tendency of not having any bony bridge in lumbar spine (negative predictive value: 92.24\%, OR 28.1, 95\% Cl:16.3-48.4, p=0.000). We analyzed the correlation between the flexion score of Bath AS Metrology Index (BASMI) 10 and the site of ankylosis. FJ ankylosis showed the strongest correlation with lumbar flexion range $\left(R^{2}=0.456, p=0.000\right)$, but bony bridge of LV and $A V$ showed weak correlation with that (respectively, $R^{2}=0.288$, $\left.\mathrm{R}^{2}=0.155, \mathrm{p}=0.000\right)$. We analyzed the correlation between ankylosis of $\mathrm{FJ}$ and bony bridge of $\mathrm{AV}$ or LV respectively. Ankylosis of $\mathrm{FJ}$ and bony bridge of $L V$ showed a stronger correlation $\left(R^{2}=0.712, p=0.000\right)$ than that of $\mathrm{AV}\left(\mathrm{R}^{2}=0.515, \mathrm{p}=0.000\right)$

Frequency of bony bridge according to vertebral level

Correlation between ant. flexion and site of spinal ankylosis
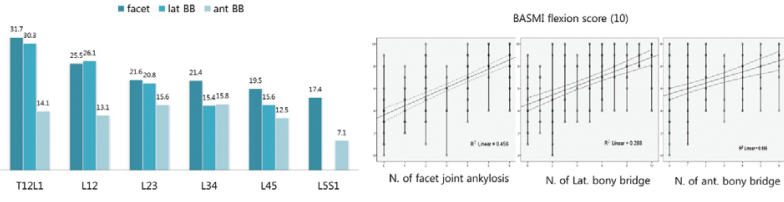

Conclusion: Bony bridge in LV is not only more developed and correlated with ankylosis in FJ, but also more correlated with limitation of anterior lumbar flexion than that in AV. We suggest bony changes of LV should be also included in radiographic score system for more sensitive detection of radiographic progression in AS.

Disclosure of Interests: None declared

DOI: 10.1136/annrheumdis-2019-eular.2020

\section{AB0734C REMISSION IN AXIAL SPONDYLOARTHRITIS: A DELPHI- METHOD QUESTIONNAIRE AMONG EXPERTS TO EVALUATE THE AVAILABLE ASSESSMENT TOOLS TO MEASURE DISEASE ACTIVITY AND TO DEVELOP A CONSENSUS DEFINITION OF REMISSION}

Xavier Juanola-Roura ${ }^{1}$, Eduardo Collantes-Estevez ${ }^{2}$, Jordi Gratacos-Masmitja ${ }^{3}$, Cristina Fernández-Carballido ${ }^{4}$, Pedro Zarco-Montejo ${ }^{5}$. ${ }^{1}$ Hospital Universitari de Bellvitge, L'Hospitalet de Llobregat, Spain; ${ }^{2}$ Reina Sofia University Hospital, Córdoba, Spain; ${ }^{3}$ Hospital Parc Taulí, Sabadell, Spain; ${ }^{4}$ Hospital Sant Joan Alacant, San Juan de Alicante, Spain; ${ }^{5}$ Fundación Hospital Alcorcón, Alcorcón, Spain

Background: Several definitions of remission in axial spondyloarthritis (axSpA) have been proposed based on the available disease activity assessment tools, but to date we lack a universally accepted definition of remission for the development of clinical trials or routine clinical practice. Objectives: To explore the degree of agreement that exists among the experts managing patients with axSpA regarding the assessment tools available to evaluate disease activity in these patients and to develop a consensus definition of clinical remission in axSpA

Methods: As a consensus method, we followed the modified Delphi methodology. A scientific committee developed 80 statements that were submitted in 2 rounds (in September and October 2018, respectively) to a panel of 152 rheumatologists from GRESSER (GRupo de Estudio de ESpondiloartritis de la Sociedad Española de Reumatología), the Spanish working group with common interests in spondyloarthritis, addressing controversial issues regarding the current assessment of remission; clinical features, laboratory and imaging tests results, and if they should be 
included in the definition of remission; general recommendations for outpatient visits and the use of disease activity scores.

Results: Agreement was reached for 56 of the 80 proposed items (70\%) The panelists concluded that although a definition of remission in axSpA is not currently available, there is consensus that it is possible to achieve remission in this disorder. There was agreement that the definition of remission in axSpA should include: pain, fatigue, functional impairment, mobility, extra-articular manifestations, peripheral involvement, joint inflammation, disease activity, laboratory tests, quality of life, need for treatment, progression of the disease, and both physician and patient global assessments. It is recommended to set a therapeutic goal when starting treatment in patients with axSpA, the ideal objective being remission, but low disease activity (LDA) may also be acceptable as an alternative objective, being ASDAS the preferred tool to assess disease activity with cut-off values of $<1.3$ for remission and $>1.3$ to $<2.1$ for LDA. A proposal for clinical remission in axSpA based on the ASDAS cut-off value associated to the absence of extra-articular (psoriasis, uveitis, inflammatory bowel disease) and peripheral (arthritis, enthesitis, dactylitis) activity, as well as the absence of inflammation assessed by the normalization of CRP levels and absence of radiographic progression.

Conclusion: This work offers consensus recommendations and a proposal of clinical remission that may be useful in the management of patients with axSpA

Disclosure of Interests: Xavier Juanola-Roura: None declared, Eduardo Collantes-Estevez: None declared, Jordi Gratacos-Masmitja Grant/research support from: Pfizer Inc, Consultant for: Pfizer Inc, Speakers bureau: Pfizer Inc, Cristina Fernández-Carballido: None declared, Pedro ZarcoMontejo: None declared

DOI: 10.1136/annrheumdis-2019-eular.2361

\section{Psoriatic arthritis}

\section{AB0735 SAFETY AND EFFECTIVENESS OF USTEKINUMAB IN PSORIATIC ARTHRITIS. A MULTICENTRIC STUDY}

Ana Belén Azuaga-Piñango ${ }^{1}$, Beatriz Frade-Sosa ${ }^{1}$, Ana Laiz ${ }^{2}$, Paula Estrada ${ }^{3}$ Luciano Polino ${ }^{4}$, Emma Beltrán ${ }^{4}$, Águeda Prior-Español ${ }^{5}$, Lourdes Mateo Soria ${ }^{5}$ Carme Moragues Pastor ${ }^{6}$, Agusti Sellas-Fernández ${ }^{7}$, Ana Urruticoechea-Arana ${ }^{8}$, Mireia Moreno ${ }^{9}$, Javier Garcia Miguel ${ }^{10}$, José L. Tandaipan ${ }^{11}$, Manel Pujol ${ }^{11}$, Vicenç Torrente Segarra ${ }^{12}$, Inmaculada Ros Vilamajo ${ }^{13}$, Sergi Ordoñez ${ }^{14}$, Delia Reina-Sanz ${ }^{15}$, Andrea Cuervo ${ }^{1}$, Juan D. Cañete ${ }^{1}$, Julio Ramirez ${ }^{1}$, ESPOCAT. ${ }^{1} \mathrm{H}$. Clinic, Rheumatology, Barcelona, Spain; ${ }^{2} \mathrm{H}$. Sant Pau, Barcelona, Spain; ${ }^{3}$ H. M. Broggi, Rheumatology, Barcelona, Spain; ${ }^{4}$ H. Mar, Rheumatology, Barcelona, Spain; ${ }^{5} \mathrm{H}$. Germans Trias i Pujol, Rheumatology, Barcelona, Spain; ${ }^{6} \mathrm{H}$. Plató, Rheumatology, Barcelona, Spain; ${ }^{7} \mathrm{H}$. Vall d'Hebron, Rheumatology, Barcelona, Spain; ${ }^{8} \mathrm{H}$. Can Misses, Rheumatology, Ibiza, Spain; ${ }^{9} \mathrm{H}$. Parc Taulí, Rheumatology, Barcelona, Spain; ${ }^{10} \mathrm{H}$. Sagrat Cor, Rheumatology, Barcelona, Spain; ${ }^{11} \mathrm{H}$. MútuaTerrassa, Rheumatology, Terrassa, Spain; ${ }^{12} \mathrm{H}$. l'Alt Penedès, Rheumatology, Villafranca, Spain; ${ }^{13} \mathrm{H}$. Son Llàtzer, Rheumatology, Mallorca, Spain; ${ }^{14} \mathrm{H}$. Arnau de Vilanova, Rheumatology, Lleida, Spain; ${ }^{15} \mathrm{H}$ Moisés Broggi, Barcelona, Spain

Background: Ustekinumab (UST) is an anti- interleukin (IL) 12/23 monoclonal antibody that has been shown to be effective and safe in psoriatic arthritis (PsA) in two phases III clinical trials. However, we have very few UST data in a real- life setting.

Objectives: To assess the effectiveness, safety and survival of UST among patients with PsA treated under routine clinical care.

Methods: Retrospective and multicentric study. Epidemiological and clinical data were collected through the electronic medical record of all patients with PSA who started UST due to rheumatological indication in 14 hospitals of Catalonia and the Balearic Islands (Spain).

Results: 152 patients were included, 116 (76.3\%) with $45 \mathrm{mg}$ and 36 $(23.8 \%)$ with $90 \mathrm{mg}$. $55.9 \%$ were women, mean age 54.79 (12.5) years, and mean disease duration 209 months. 132 patients (87\%) had oligo $(30.3 \%)$ or polyarticular involvement $(56.6 \%)$. $26.8 \%$ had enthesitis and $36.2 \%$ dactylitis. $48 \mathrm{p}(35.6 \%)$ had erosions. $94 \mathrm{p}(61.8 \%)$ had previously received another biological therapy, and 39 of them $(38.8 \%)$ had received 2 or more. $54.6 \%$ of the patients were taking DMARDs and $39.5 \%$ glucocorticoids. The baseline DAS 28 was 3.97 (1.45), C reactive protein (CRP) was $2 \mathrm{mg} / \mathrm{dl}$ (2), SJC was 4.0 (5.4), and PASI was 6.5 (8.4). There were no significant differences in clinical and epidemiological data between patients at 45 or $90 \mathrm{mg}$ except in obese patients $(58.4 \%$ in
$90 \mathrm{mg}$ vs $40 \%$ in $45 \mathrm{mg}, \mathrm{p}=0.038$ ). Overall, there was a significant decrease in DAS28, SJC, TJC and PASI in the first month of treatment, with more pronounced improvement in skin (PASI and BSA) than in joints outcomes, where the curves reached a plateau at 6 months. There were no significant differences between joint and/or skin outcomes between 45 and $90 \mathrm{mg}$ doses.

Patients naive to biological therapy had an earlier skin improvement than patients with previous biological failure. Likewise, the improvement in joint outcomes was also faster in naive vs biological experienced patients (DAS28 and SJC $4 \mathrm{~m}, \mathrm{p}=0.01$ and 0.01 , respectively).

After an average of $19 \mathrm{~m}$ of follow-up, 94 out of $152 \mathrm{p}(61.8 \%)$ continued with UST, $54.4 \%$ started at $45 \mathrm{mg}$ and $72.2 \%$ at $90 \mathrm{mg}(p=0.04)$. $42 \mathrm{p}$ $(28.2 \%)$ stopped UST due to joint inefficacy, 8p (5.4\%) for skin inefficacy and $4(2.7 \%)$ for adverse effect. Although survival was better in patients with fewer previous biological agents, no significant differences were achieved $(p=0.233$ for naive and $p=0.072$ for patients with 1 biological failure).

Conclusion: This analysis demonstrates that UST, administered to PSA patients in a routine clinical care setting, is safe and effective in improving skin and joint outcomes. $61.2 \%$ of the patients continued with the treatment after an average of $19 \mathrm{~m}$ of follow-up. Joint and skin outcomes reached significant differences from the first month. The efficacy seems faster in those patients with fewer lines of previous biological therapies. One third of the patients interrupted the therapy due to joint inefficacy.

Acknowledgement: JANSSEN

Disclosure of Interests: Ana Belén Azuaga-Piñango: None declared, Beatriz Frade-Sosa: None declared, Ana Laiz Consultant for: Lilly, Novartis, AbbVvie, MSD, UCB and Janssen, Speakers bureau: Lilly, Novartis, Abv vie, MSD, UCB and Janssen, Paula Estrada: None declared, Luciano Polino: None declared, Emma Beltrán: None declared, Águeda Prior-Espa ñol: None declared, Lourdes Mateo Soria: None declared, Carme Moragues Pastor : None declared, Agusti Sellas-Fernández: None declared, ANA URRUTICOECHEA-ARANA: None declared, Mireia Moreno - None declared, Javier Garcia Miguel: None declared, José L Tandaipan: None declared, Manel Pujol: None declared, Vicenç Torrente Segarra None declared, Inmaculada Ros Vilamajo : None declared, Sergi Ordoñez : None declared, Delia Reina-Sanz: None declared, Andrea Cuervo: None declared, Juan D. Cañete: None declared, Julio Ramirez: None declared DOI: 10.1136/annrheumdis-2019-eular.4877

\section{AB0736 GENDER INFLUENCE ON TREATMENT EFFECTIVENESS IN PSORIATIC ARTHRITIS}

Diego Benavent, Chamaida Plasencia, Victoria Navarro-Compán, Alejandro Villalva, Diana Peiteado, Gemma Bonilla, Elisa Fernández, Alejandro Balsa. Hospital La Paz, Rheumatology, Madrid, Spain

Background: Gender has been lately suggested as influential in the response to treatment with biological drugs in spondyloarthritis, such as psoriatic arthritis (PsA). However, data about the association between gender and treatment response in axial PsA (axPsA) or peripheral PsA (pPsA) are scarce.

Objectives: To analyze the association between gender and clinical response to biological therapy in patients with axPsA and pPsA.

Methods: An observational cohort study was conducted, prospectively collecting data from 108 patients treated with biological therapy (93\% TNF and $7 \% \quad \mathrm{IL}-17 \mathrm{i})$ from 2002-2018. Patients were divided into two groups according to their clinical predominant manifestation: axPsA or pPsA. Dis ease activity indexes (ASDAS and BASDAI for axPsA and DAPSA and DAS28 for PSA) were collected before starting drug and 6 months later (baseline and $6 \mathrm{~m}$ visit, respectively). Low disease activity (LDA) was defined as ASDAS $<2.1$ or BASDAI $<4$ (axPsA) and DAPSA $\leq 14$ or DAS28 $\leq 3.2$ (pPsA). Clinical improvement was defined as an improve ment $\geq 1.1$ points in ASDAS (dASDAS) or $50 \%$ in BASDAI (BASDAI50) for axPsA, and an improvement of $50 \%$ in DAPSA (DAPSA50) or dDAS28 $>1.2$. First, the frequency of male- and female-patients achieving LDA and clinical improvement at $6 \mathrm{~m}$ were compared using Fisher test, separately for axPsA and pPsA. Second, the association between gender and each of the clinical outcomes was analyzed using logistic regression models adjusted for confounders (age, disease duration, previous biologics, smoking habit, body mass index (BMI), baseline DMARDs and baseline disease activity (ASDAS or BASDAI for axPsA and DAPSA or DAS28 for pPsA).

Results: Out of 108 included patients, 55 (51\%) had predominant axPsA and $54(49 \%)$ pPsA. In the group of axPsA, $35(64 \%)$ were males, 33 